Original Paper

\title{
Performance Evaluation of an Improved GC-MS Method to Quantify Methylmercury in Fish
}

\author{
Takahiro Watanabe ${ }^{*, 1}$, Hiroyuki KikUchi ${ }^{1}$, Rieko Matsuda ${ }^{1}$, \\ Tomoko HaYashi ${ }^{1}$, Koichi Akaki ${ }^{2}$ and Reiko Teshima ${ }^{1}$ \\ ${ }^{1}$ National Institute of Health Sciences: 1-18-1 Kamiyoga, Setagaya-ku, Tokyo 158-8501, Japan; \\ ${ }^{2}$ Fukuoka City Institute for Hygiene and the Environment: \\ 2-1-34 Jigyohama, Chuo-ku, Fukuoka 810-0065, Japan; \\ *Corresponding author
}

\begin{abstract}
Here, we set out to improve our previously developed methylmercury analytical method, involving phenyl derivatization and gas chromatography-mass spectrometry (GC-MS). In the improved method, phenylation of methylmercury with sodium tetraphenylborate was carried out in a toluene/ water two-phase system, instead of in water alone. The modification enabled derivatization at optimum $\mathrm{pH}$, and the formation of by-products was dramatically reduced. In addition, adsorption of methyl phenyl mercury in the GC system was suppressed by co-injection of PEG200, enabling continuous analysis without loss of sensitivity. The performance of the improved analytical method was independently evaluated by three analysts using certified reference materials and methylmercury-spiked fresh fish samples. The present analytical method was validated as suitable for determination of compliance with the provisional regulation value for methylmercury in fish, set in the Food Sanitation haw.
\end{abstract}

(Received November 7, 2014)

Key words: methylmercury; phenyl derivatization; GC-MS; fresh fish

\section{Introduction}

Methylmercury, an organomercury compound, has adverse health effects, such as marked distal sensory disturbances, constriction of visual field, ataxia, dysarthria, auditory disturbances, and tremors, due to its action on the central nervous system ${ }^{1)}{ }^{2}$. The central nervous system of the developing fetus, in which the blood-brain barrier function is not fully developed, is reported to be particularly vulnerable ${ }^{* 1, * 2}$. Due to concerns over adverse health effects, international organizations and governments have issued warnings regarding the consumption of methylmercury-contaminated foods, particularly fish and shellfish. In March of 2004, the Joint FAO/WHO Expert Committee on Food Additives (JECFA) lowered the provisional tolerable weekly intake of methylmercury from 3.3 to $1.6 \mu \mathrm{g} / \mathrm{kg}$ body weight/week. Also in 2004, the U.S. Food and Drug Administration revised its advice and recommended that pregnant women limit their consumption of specific kinds of fish and

* E-mail: tawata@nihs.go.jp

*1 "Food Safety Risk Assessment Related to Methylmercury in Seafood", Food Safety Commission of Japan, Tokyo. (2005). https://www.fsc.go.jp/english/topics/methylmercury risk_assessment.pdf

*2 "Methylmercury; Environmental Health Criteria 101", WHO, Geneva (1990). http://www.inchem.org/documents/ ehc/ehc/ehc101.htm shellfish $^{* 3}$. On June 3, 2003, the Ministry of Health, Labour and Welfare of Japan (MHLW) issued its "Advice on Fish Consumption and Mercury". In 2005, MHLW also issued a modified proposal, "Advice for Pregnant Women on Fish Consumption and Mercury"*4.

In 1973, MHLW set the provisional regulation value for mercury in fish and shellfish (excepting some fish species) at $0.4 \mathrm{ppm}$ as total mercury and $0.3 \mathrm{ppm}$ as methylmercury. In the appendix to the notification in which the regulation values were published, the analytical method for methylmercury (hereinafter referred to as the "official method") is presented*5. In the official method, methylmercury is extracted with benzene under hydrochloric acid and then transferred to a cysteine-con-

*3 "FDA and EPA Announce the Revised Consumer Advisory on Methylmercury in Fish", U.S. Food and Drug Administration and Environment Protection Agency (2004). http:// www.fda.gov/NewsEvents/Newsroom/PressAnnouncements/2004/ucm108267.htm

*4 "Advice for Pregnant Women on Fish Consumption and Mercury”, Subcommittee on Animal Origin Foods, Food Sanitation Committee, Pharmaceutical Affairs and Food Sanitation Council, Ministry of Health, Labour and Welfare of Japan, Tokyo (2005). http://www.mhlw.go.jp/topics/ bukyoku/iyaku/syoku-anzen/suigin/dl/051102-1en.pdf

*5 "Provisional regulation value for mercury in fish and shellfish", The Ministry of Health and Welfare of Japan, Tokyo. Notification No. 99 (1973). 
taining aqueous solution. The methylmercury is then once again transferred to benzene by acidifying the aqueous cysteine-containing layer, and is then measured using a GC-ECD equipped with a packed column. Because benzene (a carcinogenic solvent) is used for extraction and ECD (which requires special control for its $\beta$ -ray source) is used for the measurement, the official method is not versatile. In addition, it has been reported that, depending upon the species examined, the recovery of methylmercury in analyses of fish samples using the official method may be low ${ }^{3)}$.

In order to overcome the above-mentioned drawbacks associated with the official method, method providing more efficient extraction of methylmercury was developed by employing alkaline degradation of proteins, hexane washing to remove fats, and dithizone as the complexing agent. This method was also adopted by the Japanese Ministry of the Environment*6. The method uses toluene instead of benzene; but, as in the official method, ECD is used for detection. Although a method employing inductively coupled plasma mass spectrometry for measurement of methylmercury has been report$\mathrm{ed}^{4)}$, the detector is not sufficiently versatile for food analysis.

The authors previously developed a versatile analytical method involving phenyl derivatization of methylmercury and subsequent measurement by GC-MS, which is widely used in food analysis ${ }^{5)}$. In the present paper, this previously reported method (hereinafter referred to as the "original method") was improved to achieve the level of performance necessary for use in determining compliance with the provisional regulation value for methylmercury. The improved method was validated.

\section{Materials and Methods}

\section{Samples}

Certified reference materials (CRM) for validation (CRM 7402-a: cod fish powder; BCR-463: tuna fish powder; ERM-CE464: tuna fish powder; and CRM 7403-a: swordfish powder) were purchased from Seishin Trading Co., Ltd. Fresh fish samples (cod, tuna, mackerel, and bonito) were purchased at a supermarket in Tokyo.

\section{Reagents}

Methylmercury chloride was obtained from GL Sciences Inc. (Tokyo, Japan). Potassium bromide, anhydrous copper(II) sulfate, sulfuric acid, cysteine hydrochloride monohydrate, sodium acetate trihydrate, sodium dihydrogen phosphate dihydrate, disodium hydrogen phosphate dodecahydrate, sodium tetraphenylborate, and polyethylene glycol (PEG) 200 were obtained from Wako Pure Chemical Industries, Ltd. (Tokyo, Japan). Other reagents were of pesticide residue analysis grade or special grade. Ultrapure water was produced using a MilliQ purification system (Element 10) (Merck Millipore,

\footnotetext{
*6 "Mercury Analysis Manual", 2004, Ministry of the Environment of Japan, Tokyo (2004). http://www.nimd.go.jp/ kenkyu/docs/march_mercury_analysis_manual\%28e\%29.pdf
}

Billerica, MA, USA).

A methylmercury standard stock solution $(1,000 \mu \mathrm{g} / \mathrm{mL})$ was prepared by accurately weighing $58.2 \mathrm{mg}$ of methylmercury chloride, dissolving it in toluene and adjusting the final volume to $50 \mathrm{~mL}$ with toluene. A methylmercury standard solution for spiking $(3 \mu \mathrm{g} / \mathrm{mL})$ was prepared by accurately weighing $58.2 \mathrm{mg}$ of methylmercury chloride, dissolving it in water and accurately adjusting the volume to $500 \mathrm{~mL}$, and then diluting $3 \mathrm{~mL}$ of this solution to a final volume of $100 \mathrm{~mL}$ with water. A $1 \mathrm{~mol} / \mathrm{L}$ potassium bromide solution was prepared by dissolving potassium bromide in water. Copper(II) sulfate-saturated $4 \mathrm{~mol} / \mathrm{L}$ sulfuric acid was prepared by adding $200 \mathrm{~mL}$ of concentrated sulfuric acid to $600 \mathrm{~mL}$ of water, allowing it to cool, adjusting the volume to $900 \mathrm{~mL}$ with water, and dissolving anhydrous copper(II) sulfate until the solution was saturated. A $1 \%$ L-cysteine solution was prepared by dissolving $10.0 \mathrm{~g}$ of L-cysteine hydrochloride monohydrate, $8.0 \mathrm{~g}$ of sodium acetate trihydrate, and $125.0 \mathrm{~g}$ of anhydrous sodium sulfate in water and adjusting the final volume to $1 \mathrm{~L}$. Sodium phosphate buffer (0.2 mol/L; pH 7.0) was prepared by mixing $0.2 \mathrm{~mol} / \mathrm{L}$ sodium dihydrogen phosphate (acidic solution) and $0.2 \mathrm{~mol} / \mathrm{L}$ disodium hydrogen phosphate (basic solution) to give $\mathrm{pH} 7.0$.

A 1\% sodium tetraphenylborate solution was prepared by dissolving $0.2 \mathrm{~g}$ of sodium tetraphenylborate in phosphate buffer $(0.2 \mathrm{~mol} / \mathrm{L} ; \mathrm{pH} 7.0)$. The $1 \%$ sodium tetraphenylborate solution was prepared immediately before use. A $1.5 \mathrm{mg} / \mathrm{mL}$ solution of PEG200 was prepared by dissolving PEG200 in toluene.

\section{Equipment}

The centrifuge used was a Model 6200 from Kubota Corporation (Tokyo, Japan). The homogenizer used was GM200 from Verder Scientific Co., Ltd. (Tokyo, Japan). The GC-MS used was a 6890 N GC \& 5975 MSD from Agilent Technologies, Inc. (Santa Clara, CA, USA).

The following conditions were used for GC-MS measurement: InertCap 5MS/NP $(0.25 \mathrm{~mm}$ i.d. $\times 30 \mathrm{~m}$ long, $0.25 \mu \mathrm{m}$ film thickness) column (GL Sciences Inc.); oven temperature, $70^{\circ} \mathrm{C}(1 \mathrm{~min}) \rightarrow 20^{\circ} \mathrm{C} / \mathrm{min} \rightarrow 280^{\circ} \mathrm{C}(5 \mathrm{~min})$; injection port temperature, $250^{\circ} \mathrm{C}$; transfer line temperature, $280^{\circ} \mathrm{C}$; ion source temperature, $230^{\circ} \mathrm{C}$; injection volume, $1 \mu \mathrm{L}$; carrier gas flow rate, $1.0 \mathrm{~mL} / \mathrm{min}(\mathrm{He})$; ionization method, EI; analysis mode, SIM; ions monitored, $m / z 292$ (quantitation ion), 294, and 277.

\section{Analytical procedure}

A sample of fresh fish was homogenized and $10.0 \mathrm{~g}$ of the homogenized sample was weighed and used for further analyses. A portion of CRM (1.0 g) was weighed and mixed with $9.0 \mathrm{~g}$ of water. Each sample was shaken with $100 \mathrm{~mL}$ acetone for $30 \mathrm{sec}$, and centrifuged. The supernatant was removed. $100 \mathrm{~mL}$ of toluene was added to the residue and the mixture was shaken for $30 \mathrm{sec}$, then centrifuged, and the supernatant was removed. The acetone- and toluene-washed residue was shaken with $40 \mathrm{~mL}$ of $1 \mathrm{~mol} / \mathrm{L}$ potassium bromide solution, $40 \mathrm{~mL}$ of 
copper(II) sulfate-saturated $4 \mathrm{~mol} / \mathrm{L}$ sulfuric acid, and $80 \mathrm{~mL}$ of toluene, and centrifuged. The toluene layer was collected. To the remaining water layer, $50 \mathrm{~mL}$ of toluene was added. The mixture was shaken for $10 \mathrm{~min}$, and the toluene layer was collected after centrifugation and combined with the previous toluene layer. To the combined toluene layers, $50 \mathrm{~mL}$ of $1 \%$ L-cysteine solution was added and the mixture was shaken for 5 min. After being allowed to stand, the water layer was collected, and $30 \mathrm{~mL}$ of $6 \mathrm{~mol} / \mathrm{L}$ hydrochloric acid and $30 \mathrm{~mL}$ of toluene were added. The sample was shaken for $5 \mathrm{~min}$, and the toluene layer was collected. This procedure was repeated three times, and the volume of the combined toluene layers was adjusted to $100 \mathrm{~mL}$ with toluene. A 4-mL aliquot was removed from this solution, $5 \mathrm{~mL}$ of $0.2 \mathrm{~mol} / \mathrm{L}$ phosphate buffer $(\mathrm{pH} 7.0)$ and $1 \mathrm{~mL}$ of $1 \%$ sodium tetraphenylborate solution were added to it, and phenyl derivatization was carried out by shaking for $10 \mathrm{~min}$ at room temperature. The reaction solution was centrifuged, the toluene layer was dehydrated with anhydrous sodium sulfate, $1 \mathrm{~mL}$ of the solution was accurately removed, and $0.5 \mathrm{~mL}$ of $1.5 \mathrm{mg} / \mathrm{mL}$ PEG200 was accurately added to obtain a GC-MS measurement solution.

\section{Preparation of standard solutions for calibration curve}

Aliquots of methylmercury standard stock solution were diluted with toluene to prepare standard solutions of $0,5,10,25,50,75$, and $100 \mathrm{ng} / \mathrm{mL}$ for use in constructing a calibration curve. The standard solutions were then subjected to phenyl derivatization and subsequent processing identical to that of analytical samples.

\section{Preparation of blank and spiked samples}

A blank sample was prepared by sufficiently homogenizing cod or tuna muscle that was confirmed beforehand to contain less than $0.15 \mathrm{mg} / \mathrm{kg}$ of methylmercury. A spiked sample was prepared by accurately adding $1 \mathrm{~mL}$ of a $3 \mu \mathrm{g} / \mathrm{mL}$ aqueous methylmercury solution to $10.0 \mathrm{~g}$ of the blank sample homogenate, mixing well, and allowing the sample to stand for 30 min prior to analysis.

\section{Method validation}

Four different CRMs and two different spiked samples were analyzed, and the trueness and precision (repeatability and intralaboratory reproducibility) were estimated. For the CRMs and spiked samples, two parallel analyses per day were carried out for 5 days. Simultaneously, two parallel analyses per day of the blank sample were carried out for 5 days. The analytical result for each spiked sample was obtained by subtracting the mean of the results obtained from analysis of the blank sample from the result for each individual spiked sample. One-way analysis of variance was performed for the 10 analytical results. The validation was independently carried out by three analysts (A, B, and C). Analysts A and $\mathrm{B}$ carried out the validation using CRMs and spiked samples in the same laboratory (laboratory I), whereas analyst $\mathrm{C}$ carried out the validation using CRMs in a different laboratory (laboratory II). The validity of the analytical method was confirmed by comparing the estimates of trueness and precision with the performance criterion shown in Notification No. 0926001, "Guidelines for the validation of analytical methods for testing metals in food"*7.

\section{Results}

\section{Improvement of pretreatment and extraction procedure}

In the original method, $1 \mathrm{~mol} / \mathrm{L}$ potassium bromide solution and copper(II) sulfate-saturated $4 \mathrm{~mol} / \mathrm{L}$ sulfuric acid were added to samples and methylmercury was extracted with toluene. Depending on the fish species analyzed, this sometimes resulted in substantial emulsion generation during extraction, greatly compromising the efficiency of the extraction procedure. Therefore, sample pretreatment using acetone and toluene, as employed in a collaborative study to validate a quantitative method for methylmercury ${ }^{6}$, was investigated for its potential to prevent emulsion generation. For pretreatment, $100 \mathrm{~mL}$ of acetone was added to a sample and then removed after shaking for $30 \mathrm{sec}$, followed by similar addition and removal of $100 \mathrm{~mL}$ of toluene. This resulted in a dramatic reduction in the frequency of emulsion generation in samples prepared from cod, tuna, mackerel, and bonito.

\section{Optimization of phenyl derivatization conditions}

In the original method, phenyl derivatization was carried out by transferring methylmercury to a $1 \%$ L-cysteine solution after toluene extraction, adding and mixing Walpole buffer ( $\mathrm{pH} 1.0$ ), adding $n$-heptane and $2 \%$ sodium tetraphenylborate solution, and then allowing the mixture to stand for $1 \mathrm{hr}$ in a $30^{\circ} \mathrm{C}$ water bath with mixing every $10 \mathrm{~min}$. However, repeated injection of measurement solutions prepared according to this procedure ultimately resulted in a significant reduction in GC-MS sensitivity, which was thought to be due to adsorption of various phenyl compounds generated by the decomposition of tetraphenylborate (e.g., biphenyl) on parts of the instrument, such as liners. In order to avoid this decrease in sensitivity, reaction conditions that would reduce the amount of degradation products formed without impacting on the phenylation efficiency were investigated (sodium tetraphenylborate concentration, $\mathrm{pH}$, reaction temperature, and reaction time). The generation of biphenyl, the degradation product formed in the highest amount, was used as an indicator to assess the effect of modifying the reaction conditions. We found that when the concentration of sodium tetraphenylborate was reduced from 2 to 1\%, the efficiency of phenyl derivatization did not change. Therefore, the sodium tetraphenylborate concentration was set at $1 \%$ to decrease the amount of by-products formed.

The effect of $\mathrm{pH}$ on phenyl derivatization efficiency

\footnotetext{
*7 "Guidelines for the validation of analytical methods for testing metals in food", The Ministry of Health, Labour and Welfare of Japan, Tokyo. Notification No. 0926001 (2012).
} 
was next investigated in reactions carried out at $30^{\circ} \mathrm{C}$ by adding $5 \mathrm{~mL}$ of buffers of different $\mathrm{pH}, 1 \mathrm{~mL}$ of $1 \%$ sodium tetraphenylborate solution, and $2.5 \mathrm{~mL}$ of $n$-heptane to $1 \mathrm{~mL}$ of $100 \mathrm{ng} / \mathrm{mL}$ methylmercury solution. The following buffers were evaluated: $0.2 \mathrm{~mol} / \mathrm{L}$ phosphate buffer at $\mathrm{pH} 2,3,4,6,7,8,11$, and $12 ; 0.2 \mathrm{~mol} / \mathrm{L}$ acetate buffer at $\mathrm{pH} 4,5$, and 6 ; and $0.2 \mathrm{~mol} / \mathrm{L}$ Tris buffer at $\mathrm{pH}$ 7,8 , and 9 . The effect of reaction time was investigated at reaction times of $0,10,20$, and $30 \mathrm{~min}$. For 0 time reaction, centrifugation was performed immediately after mixing of all solutions and solvent. Figure 1 shows the peak areas for methyl phenyl mercury and biphenyl generated by phenyl derivatization under various conditions. With increasing $\mathrm{pH}$, the methyl phenyl mercury peak area decreased. However, the degree of the change was small, and the peak area for reaction at $\mathrm{pH} 7$ was about $90 \%$ of that at $\mathrm{pH} 2$. In contrast, the biphenyl peak area was greatest at $\mathrm{pH} 2$, declined steeply up to $\mathrm{pH}$, and was negligibly small at higher pHs. The methyl phenyl mercury peak area remained relatively constant regardless of the reaction time, and the reaction was considered to proceed quickly. In contrast, the bi- phenyl peak area increased as the reaction time increased. No difference in the methyl phenyl mercury peak area was observed at reaction temperatures of 25 , 30 , and $40^{\circ} \mathrm{C}$. Based on these results, phenyl derivatization reactions were carried out with $1 \%$ sodium tetraphenylborate solution in $0.2 \mathrm{~mol} / \mathrm{L}$ phosphate buffer $(\mathrm{pH}$ 7.0) with shaking for $10 \mathrm{~min}$ at room temperature.

Subsequently, it was confirmed that under the above reaction conditions, methylmercury can be phenylated even in organic solvent, similarly to aqueous solutions. Toluene was selected as the organic solvent because it permits easy transfer of methylmercury. To $2.5 \mathrm{~mL}$ of a $40 \mathrm{ng} / \mathrm{mL}$ solution of methylmercury in toluene, $5 \mathrm{~mL}$ of $0.2 \mathrm{~mol} / \mathrm{L}$ phosphate buffer $(\mathrm{pH} 7.0)$ and $1 \mathrm{~mL}$ of $1 \%$ sodium tetraphenylborate solution were added and reacted by shaking for $10 \mathrm{~min}$, after which the toluene layer was collected (condition A). At the same time, to $2.5 \mathrm{~mL}$ of $40 \mathrm{ng} / \mathrm{mL}$ methylmercury in $0.2 \mathrm{~mol} / \mathrm{L}$ phosphate buffer ( $\mathrm{pH} 7.0), 2.5 \mathrm{~mL}$ of $0.2 \mathrm{~mol} / \mathrm{L}$ phosphate buffer ( $\mathrm{pH} 7.0$ ), $1 \mathrm{~mL}$ of $1 \%$ sodium tetraphenylborate solution, and $2.5 \mathrm{~mL}$ of toluene were added and reacted by shaking for $10 \mathrm{~min}$, after which the toluene layer was collected (con-
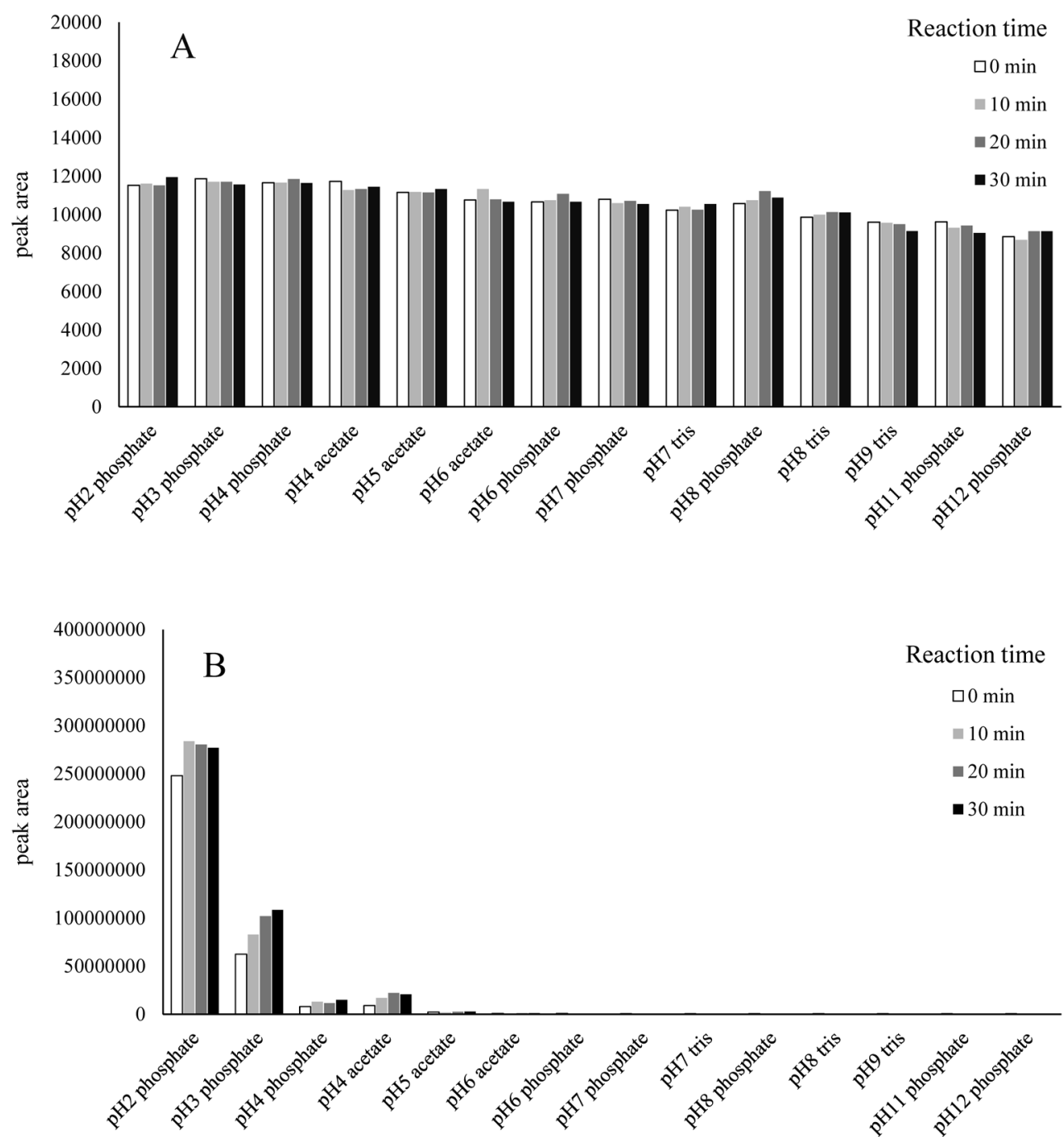

Fig. 1. Effects of $\mathrm{pH}$ and reaction time on (A) methyl phenyl mercury and (B) biphenyl GC-MS peak areas 
dition B). The methyl phenyl mercury peak area obtained was $11,134 \pm 160$ under condition $\mathrm{A}$ and was $11,311 \pm 87$ under condition $\mathrm{B}(n=3)$.

The transfer conditions of methylmercury to toluene from acidified L-cysteine solution were also investigated. L-cysteine solution was acidified with $30 \mathrm{~mL}$ of $6 \mathrm{~mol} / \mathrm{L}$ hydrochloric acid, and methylmercury was extracted with $30 \mathrm{~mL}$ of toluene three times. The transfer rate was evaluated based on the amount of methylmercury in toluene layers obtained in three steps. The transfer rate at the first procedure was $74.1 \%$. At the second and third times, the rate was $19.0 \%$ and $5.1 \%$, respectively. Thus, it was concluded that efficient derivatization can be achieved by using $1 \%$ sodium tetraphenylborate solution for the reaction after transfer of methylmercury in 1\% Lcysteine solution to toluene by extraction three times.

\section{Selection of PEG amount co-injected}

In GC-MS calibration curves constructed from data obtained by direct injection of methyl phenyl mercury solutions prepared by the derivatization of methylmercury, the intercept was always negative. It was suspected that a portion of the injected methyl phenyl mercury was lost by adsorption in the GC-MS instrument. Therefore, the effect of co-injecting PEG to suppress adsorption of methyl phenyl mercury was investigated. As a preliminary experiment, $1 \mathrm{~mL}$ of measurement solution prepared from $20 \mathrm{ng} / \mathrm{mL}$ methyl mercury solution was mixed with $0.5 \mathrm{~mL}$ of $1.5 \mathrm{mg} / \mathrm{mL}$ PEG200 solution or $0.5 \mathrm{~mL}$ of toluene and both mixtures were injected into the GC-MS. The peak area of the solution containing PEG was $3884 \pm 49$, while that of the solution not containing PEG was $2550 \pm 190(n=3)$. These results suggested that PEG worked as anticipated. Then, the conditions of PEG co-injection were optimized. Based on the molecular weight of methyl phenyl mercury, PEG200 and PEG300 were evaluated.

Measurement solutions containing 250, 500, or $750 \mathrm{ng}$ of PEG200 or PEG300 and methyl phenyl mercury were prepared, and $1 \mu \mathrm{L}$ of each solution was injected into the GC-MS. Although, co-injection with PEG increased the peak area about 1.5 times as described above, increasing the amount of PEG injected from 250 to $750 \mathrm{ng}$ produced only a slight increase in the methyl phenyl mercury peak area. In addition, no difference in peak area was observed between PEG200 and PEG300 (Table 1). Because the boiling point of PEG200 is lower than that of PEG300, so that the final GC column temperature can be set lower, PEG200 was selected for co-injection. In order to minimize contamination of the GC-MS instrument, the minimum effective amount of PEG200 was coinjected, which was $500 \mathrm{ng}$. No extra peaks was found on the chromatogram of methyl phenyl mercury solution (100 ng/mL as methyl mercury) co-injected with $500 \mathrm{ng}$ of PEG200 (Fig. 2)

\section{Elimination of ethylenediamine- $N$-propyl silane column} (PSA column) clean-up from the original method

In the original method, the orange pigment thought to be a reaction by-product of the phenyl derivatization of methylmercury was removed using a PSA column. In the present method, this pigment was not observed, presumably due to the improvements in the phenyl derivatization method. Therefore, we considered that removal of the PSA column purification step from the analytical procedure would be desirable from the viewpoint of labor reduction. However, it was unclear whether or not the matrix derived from the sample and any remaining derivatization reagent need to be removed. To address this issue, measurement solutions prepared using various fish samples (cod, tuna, mackerel, and bonito) were analyzed after purification using a PSA column and the results were compared with those of measurement solutions not subjected to PSA purification. A measurement solution prepared from methylmercury standard solution was similarly measured as a control. No difference was observed between the chromatograms of the methylmercury standard solution and those of the fish samples. The ratios of the methyl phenyl mercury peak areas for the measurement solutions prepared with and without PSA column purification from methylmercury standard, cod, tuna, mackerel, and bonito were in

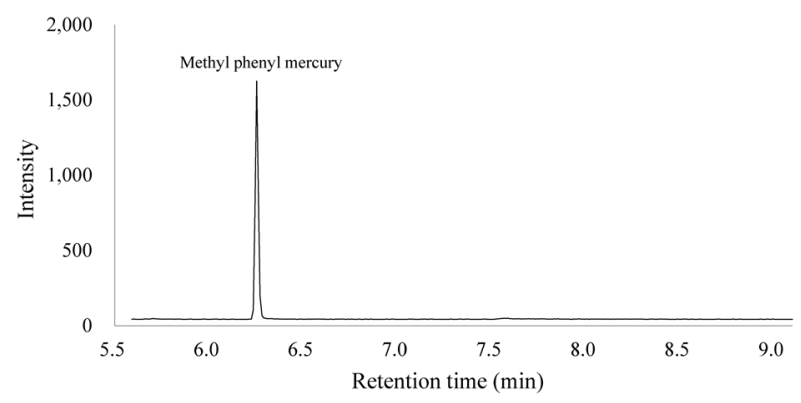

Fig. 2. GC chromatogram obtained from methyl phenyl mercury co-injected with 500 ng of PEG200

Table 1. Comparison of GC-MS peak areas for methyl phenyl mercury co-injected with different amounts of PEG200 or 300

\begin{tabular}{|c|c|c|c|c|c|c|}
\hline \multirow{3}{*}{$\begin{array}{l}\text { Methcyl mercury } \\
\quad(\mathrm{ng} / \mathrm{mL})\end{array}$} & \multicolumn{6}{|c|}{ Peak area of methyl phenyl mercury } \\
\hline & \multicolumn{3}{|c|}{ Amount of PEG200 co-injected (ng) } & \multicolumn{3}{|c|}{ Amount of PEG300 co-injected (ng) } \\
\hline & 250 & 500 & 750 & 250 & 500 & 750 \\
\hline 0 & - & - & - & - & - & - \\
\hline 2.5 & 460 & 480 & 513 & 452 & 459 & 507 \\
\hline 100 & 18,597 & 18,754 & 19,269 & 18,642 & 18,976 & 19,389 \\
\hline
\end{tabular}

-: signal not detected 
the range of 1.00-1.01 in all cases. Thus, the use of a PSA column to remove the pigment had only a minimal effect on both the chromatograms and the peak areas, and as the degree of purification afforded by the column was considered to be small, its use was omitted.

\section{Validation of the analytical method}

The trueness, repeatability, and intralaboratory reproducibility estimated based on the analytical results for four different CRMs are shown in Table 2. The same parameters estimated based on the analytical results for two different spiked samples are shown in Table 3 Trueness is the closeness of agreement between the average of the analytical results and the reference quantity value (certified level for CRMs or the spiked level) in this study. Repeatability is estimated as the standard deviation of the analytical results obtained in repeated determinations. Intralaboratory reproducibility is one kind of estimate of intermediate precision, and is estimated as the standard deviation of the analytical results under intralaboratory condition in this study. The trueness estimated from analysis of the certified reference

Table 2. Trueness, repeatability and intralaboratory reproducibility estimated by analysis of certified reference materials

\begin{tabular}{|c|c|c|c|c|c|c|c|c|c|c|c|c|}
\hline \multirow{2}{*}{ Sample } & \multirow{2}{*}{$\begin{array}{l}\text { Certified } \\
\text { level } \\
(\mathrm{mg} / \mathrm{kg})\end{array}$} & \multirow{2}{*}{ Analyst } & & \multicolumn{6}{|c|}{ Result (mg/kg) } & \multirow{2}{*}{$\begin{array}{c}\text { Trueness } \\
(\%)\end{array}$} & \multirow{2}{*}{$\begin{array}{l}\text { Repeatability } \\
\text { (RSD\%) }\end{array}$} & \multirow{2}{*}{$\begin{array}{l}\text { Intralaboratory } \\
\text { reproducibility } \\
\quad(\mathrm{RSD} \%)\end{array}$} \\
\hline & & & & $1 \mathrm{st}$ & 2nd & $3 \mathrm{rd}$ & 4 th & 5 th & average & & & \\
\hline \multirow{6}{*}{$\begin{array}{c}\text { CRM } \\
7402-\mathrm{a}\end{array}$} & \multirow{6}{*}{$\begin{array}{l}0.58 \pm 0.02 \\
\quad \text { (as Hg) }\end{array}$} & \multirow{2}{*}{$\mathrm{A}$} & Portion 1 & 0.5261 & 0.4763 & 0.5013 & 0.5072 & 0.4982 & \multirow{2}{*}{0.504} & \multirow{2}{*}{87} & \multirow{2}{*}{0.8} & \multirow{2}{*}{3.9} \\
\hline & & & Portion 2 & 0.5347 & 0.4771 & 0.5036 & 0.5108 & 0.5074 & & & & \\
\hline & & \multirow{2}{*}{ B } & Portion 1 & 0.5685 & 0.5397 & 0.5518 & 0.5102 & 0.5339 & \multirow{2}{*}{0.544} & \multirow{2}{*}{94} & \multirow{2}{*}{1.4} & \multirow{2}{*}{4.3} \\
\hline & & & Portion 2 & 0.5756 & 0.5595 & 0.5568 & 0.5165 & 0.5251 & & & & \\
\hline & & \multirow{2}{*}{$\mathrm{C}$} & Portion 1 & 0.5200 & 0.4816 & 0.5201 & 0.4413 & 0.4420 & \multirow{2}{*}{0.493} & \multirow{2}{*}{85} & \multirow{2}{*}{5.5} & \multirow{2}{*}{7.3} \\
\hline & & & Portion 2 & 0.5017 & 0.5085 & 0.5374 & 0.4574 & 0.5184 & & & & \\
\hline \multirow{6}{*}{$\begin{array}{c}\text { BCR- } \\
463\end{array}$} & \multirow{6}{*}{$\begin{array}{l}3.04 \pm 0.16 \\
\text { (as } \mathrm{MeHg} \text { ) }\end{array}$} & \multirow{2}{*}{ A } & Portion 1 & 3.078 & 2.952 & 3.030 & 3.091 & 3.000 & \multirow{2}{*}{2.984} & \multirow{2}{*}{98} & \multirow{2}{*}{4.6} & \\
\hline & & & Portion 2 & 3.056 & 3.137 & 2.904 & 2.910 & 2.677 & & & & 4.6 \\
\hline & & $B$ & Portion 1 & 2.997 & 2.896 & 2.841 & 2.924 & 2.865 & & & & \\
\hline & & D & Portion 2 & 2.913 & 3.079 & 2.865 & 3.055 & 3.008 & 2.944 & 97 & 3.0 & 3.0 \\
\hline & & $\mathrm{C}$ & Portion 1 & 2.959 & 2.752 & 2.788 & 2.742 & 2.677 & & & & \\
\hline & & C & Portion 2 & 2.700 & 2.664 & 2.857 & 3.263 & 2.607 & 2.801 & 92 & 6.7 & 6.8 \\
\hline & & A & Portion 1 & 5.432 & 6.032 & 5.078 & 4.942 & 5.321 & & & & \\
\hline & & A & Portion 2 & 5.316 & 5.086 & 4.866 & 4.976 & 5.205 & 5.225 & 95 & 6.0 & 6.5 \\
\hline ERM- & $5.50 \pm 0.17$ & B & Portion 1 & 5.332 & 5.287 & 4.830 & 5.150 & 5.367 & 5245 & 95 & 26 & 28 \\
\hline CE464 & (as $\mathrm{MeHg}$ ) & В & Portion 2 & 5.456 & 5.150 & 5.093 & 5.436 & 5.349 & 5.245 & 95 & 2.6 & 3.8 \\
\hline & & $\mathrm{C}$ & Portion 1 & 5.607 & 4.805 & 4.739 & 5.085 & 4.664 & 5012 & 01 & 36 & 61 \\
\hline & & C & Portion 2 & 5.341 & 4.854 & 5.180 & 4.986 & 4.872 & 5.013 & 91 & 3.6 & 6.1 \\
\hline & & A & Portion 1 & 4.562 & 4.620 & 4.419 & 4.457 & 4.433 & 4619 & 92 & 60 & 60 \\
\hline & & A & Portion 2 & 5.297 & 4.497 & 4.853 & 4.478 & 4.575 & 4.619 & 92 & 0.0 & 0.0 \\
\hline CRM & $5.00 \pm 0.22$ & B & Portion 1 & 4.752 & 4.724 & 4.701 & 4.776 & 4.839 & 4.750 & 95 & 0.9 & 1.6 \\
\hline 7403-a & (as Hg) & D & Portion 2 & 4.819 & 4.689 & 4.619 & 4.718 & 4.861 & 4.750 & 90 & 0.9 & 1.6 \\
\hline & & $\mathrm{C}$ & Portion 1 & 5.177 & 4.185 & 4.331 & 4.762 & 4.406 & 4476 & 90 & & 69 \\
\hline & & $c$ & Portion 2 & 4.600 & 4.225 & 4.285 & 4.370 & 4.416 & 4.476 & 90 & 4.9 & 6.9 \\
\hline
\end{tabular}

Table 3. Trueness, repeatability and intralaboratory reproducibility estimated by analysis of spiked samples

\begin{tabular}{|c|c|c|c|c|c|c|c|c|c|c|c|c|}
\hline \multirow{2}{*}{\multicolumn{3}{|c|}{$\begin{array}{c}\text { Spiked } \\
\text { Sample concentration Analys } \\
(\mathrm{mg} / \mathrm{kg})\end{array}$}} & & \multicolumn{6}{|c|}{ Result (mg/kg) } & \multirow{2}{*}{$\begin{array}{l}\text { Trueness } \\
\text { e } \quad(\%)\end{array}$} & \multirow{2}{*}{$\begin{array}{l}\text { Repeatability } \\
\quad(\text { RSD } \%)\end{array}$} & \multirow{2}{*}{$\begin{array}{l}\text { Intralaboratory } \\
\text { reproducibility } \\
\quad(\mathrm{RSD} \%)\end{array}$} \\
\hline & & & & $1 \mathrm{st}$ & 2nd & $3 \mathrm{rd}$ & 4 th & 5 th & average & & & \\
\hline \multirow{2}{*}{ Cod } & \multirow{2}{*}{0.3} & $\mathrm{~A}$ & $\begin{array}{l}\text { Portion } 1 \\
\text { Portion } 2\end{array}$ & $\begin{array}{l}0.2449 \\
0.2486\end{array}$ & $\begin{array}{l}0.2616 \\
0.2590\end{array}$ & $\begin{array}{l}0.2726 \\
0.2812\end{array}$ & $\begin{array}{l}0.2766 \\
0.2791\end{array}$ & $\begin{array}{l}0.2692 \\
0.2709\end{array}$ & 0.266 & 89 & 1.2 & 5.0 \\
\hline & & B & $\begin{array}{l}\text { Portion } 1 \\
\text { Portion } 2\end{array}$ & $\begin{array}{l}0.3012 \\
0.2781\end{array}$ & $\begin{array}{l}0.2879 \\
0.2855\end{array}$ & $\begin{array}{l}0.2750 \\
0.2710\end{array}$ & $\begin{array}{l}0.2814 \\
0.3111\end{array}$ & $\begin{array}{l}0.2868 \\
0.2739\end{array}$ & 0.285 & 95 & 4.4 & 4.4 \\
\hline \multirow{2}{*}{ Tuna } & \multirow{2}{*}{0.3} & A & $\begin{array}{l}\text { Portion } 1 \\
\text { Portion } 2\end{array}$ & $\begin{array}{l}0.2613 \\
0.2554\end{array}$ & $\begin{array}{l}0.2569 \\
0.2819\end{array}$ & $\begin{array}{l}0.2435 \\
0.2917\end{array}$ & $\begin{array}{l}0.2352 \\
0.2481\end{array}$ & $\begin{array}{l}0.2913 \\
0.2866\end{array}$ & 0.265 & 88 & 6.7 & 8.1 \\
\hline & & B & $\begin{array}{l}\text { Portion } 1 \\
\text { Portion } 2\end{array}$ & $\begin{array}{l}0.2672 \\
0.3004\end{array}$ & $\begin{array}{l}0.3318 \\
0.2952\end{array}$ & $\begin{array}{l}0.2663 \\
0.2694\end{array}$ & $\begin{array}{l}0.3181 \\
0.2874\end{array}$ & $\begin{array}{l}0.3058 \\
0.2991\end{array}$ & 0.294 & 98 & 6.3 & 7.6 \\
\hline
\end{tabular}


materials was $87-98 \%$ for analyst A, 94-97\% for analyst $\mathrm{B}$, and $85-92 \%$ for analyst $\mathrm{C}$. The repeatability, expressed as RSD\%, was $0.8-6.0 \%$ for analyst A, $0.9-3.0 \%$ for analyst B, and $3.6-6.7 \%$ for analyst $\mathrm{C}$. The intralaboratory reproducibility was $3.9-6.5 \%$ for analyst $\mathrm{A}, 1.6-$ $4.3 \%$ for analyst B, and $6.1-7.3 \%$ for analyst C. With respect to analyses of the spiked samples, the estimated trueness was 89 and $88 \%$ for analyst A and 95 and $98 \%$ for analyst B. The repeatability was 1.2 and $6.7 \%$ for analyst $\mathrm{A}$ and 4.4 and $6.3 \%$ for analyst $\mathrm{B}$. The intralaboratory reproducibility was 5.0 and $8.1 \%$ for analyst $\mathrm{A}$ and 4.4 and $7.6 \%$ for analyst B.

\section{Discussion}

\section{Phenyl derivatization of methylmercury}

In the original method, the conditions for the reaction of tetraphenylborate and methylmercury were investigated in the presence of L-cysteine. When the $\mathrm{pH}$ exceeded 2 , the amount of methyl phenyl mercury formed decreased. Therefore, the reaction was carried out at $\mathrm{pH}$ $0.5-1.5$ at $30^{\circ} \mathrm{C}$ for $1 \mathrm{hr}$. In this study, the effect of omitting L-cysteine from the reaction conditions was investigated. In the absence of L-cysteine, no decrease in the amount of methyl phenyl mercury formed was observed in the range of $\mathrm{pH} 2-9$. Accordingly, the reported decrease in the amount of methyl phenyl mercury formed at $\mathrm{pH} \geq 2$ with the original method was considered to be due to the formation of a complex between methylmercury and L-cysteine, and the optimum $\mathrm{pH}$ of the derivatization reaction itself was considered to be in the above-mentioned range. When the derivatization reaction was carried out in the neutral $\mathrm{pH}$ range, the amount of phenyl compounds formed, including the sodium tetraphenylborate degradation product biphenyl, decreased, and unlike the case of the original method, no formation of orange pigment was observed. Therefore, performing the derivatization reaction in the neutral $\mathrm{pH}$ range reduces the amount of undesired by-products formed without decreasing the concentration of methyl phenyl mercury in the measurement solution, thus lessening the potential for contamination of the GC instrument.

When methylmercury was extracted from a sample into the toluene layer and then transferred into water, $1 \%$ L-cysteine solution was used to increase the percentage of transfer. Under neutral $\mathrm{pH}$ conditions, L-cysteine and methylmercury form a complex, and the methylmercury contained in this complex cannot be phenylated by sodium tetraphenylborate. Therefore, phenylation of methylmercury with sodium tetraphenylborate in toluene in the absence of aqueous L-cysteine was investigated. In this case, the amount of methyl phenyl mercury formed in toluene was the same as that formed when methylmercury was phenylated in aqueous solution. In addition, the reaction proceeded easily upon shaking for $10 \mathrm{~min}$ at room temperature. It is not known whether this phenyl derivatization reaction takes place in the water layer, in the toluene layer, or at the interface between these layers.
In order to phenylate methylmercury in toluene solution, a step was added to the analytical procedure, in which methylmercury is again transferred from the Lcysteine solution to toluene. By adding this step, the need to transfer methyl phenyl mercury from the reaction solution to $n$-heptane, as was required in the original method, was eliminated.

\section{Method validation}

The following fish-based reference materials containing certified levels of methylmercury were selected for method validation: CRM 7402-a (cod fish powder), BCR463 (tuna fish powder), ERM-CE464 (tuna fish powder), and CRM 7403-a (swordfish powder). The certified levels of methylmercury in the dry state were $0.58-5.00 \mathrm{mg} / \mathrm{kg}$, concentrations close to the provisional regulation value of $0.3 \mathrm{mg} / \mathrm{kg}$ (wet weight).

The trueness, repeatability and intralaboratory reproducibility estimated by using independent analytical results obtained by three analysts (analyst A, B, and C) under various conditions were in agreement with the target values shown in the validation guidelines for test methods for metals (i.e., trueness, 80-110\%; repeatability, $<10 \%$ [RSD\%]; and intralaboratory reproducibility, $<15 \%$ [RSD\%]). The trueness estimate for the lowestconcentration of CRM7402-a sample was slightly lower than that for the other CRMs for all three analysts; but no systematic difference was observed with respect to precision.

The number of available reference materials containing certified levels of methylmercury is limited. The concentration to be confirmed by the analytical method used for the determination of compliance with the provisional regulation value may not necessarily be in agreement with the certified value. In addition, CRMs are usually expensive; thus, they are not easy to procure. Furthermore, in order to ensure test reliability, the analytical method must be validated using actual samples (wet samples of targeted fish species) before it is used to determine regulatory compliance. Therefore, the performance of the improved method was also evaluated using spiked samples. Samples usable as blanks were selected by analyzing the methylmercury content of several species of fresh fish purchased at a market. Fish found to contain less than $0.15 \mathrm{mg} / \mathrm{kg}$, which corresponds to onehalf the provisional regulation concentration, were selected for use as blanks. In the general preparation of spiked samples, it is desirable to use a solvent that is miscible with the sample; thus, an aqueous solution of methylmercury was used for this purpose.

Because some methylmercury is contained in the blank sample, variations in the concentration of mercury in the blank sample and variations arising from analysis contribute to the variations in the measured concentration of methylmercury. In order to reduce the first variation as much as possible, the blank sample was mixed to be as homogeneous as possible. The SD for the results of 10 analyses of the methylmercury concentration in the cod blank sample was $0.0028-0.007 \mathrm{mg} / \mathrm{kg}$. The SD for 
the results of 10 analyses of the methylmercury concentration in the tuna blank sample was $0.0068-0.011 \mathrm{mg} /$ $\mathrm{kg}$, slightly larger than that of the cod blank sample. The SD for the analytical results of the spiked samples was $\geq 2$ times the SD of the results for the blank samples. Thus, the contribution made by non-homogeneity of the blank sample to the precision estimates was not large.

The trueness, repeatability and intralaboratory reproducibility estimated based on the analytical results obtained by analysts A and B were similar to the values estimated from analyses of certified reference materials, in agreement with the target values specified in the guidelines. Thus, we concluded that validation of an analytical method is possible in circumstances where only samples containing the analyte are available.

\section{Conclusion}

In the present study, we improved the original method for the analysis of methylmercury in fish via phenyl derivatization and subsequent GC-MS measurement. By optimizing the phenyl derivatization reaction conditions, the formation of degradation products from the phenyl derivatization reagent could be successfully reduced. In addition, undesirable adsorption of methyl phenyl mercury within the GC-MS instrument was suppressed by the co-injection of PEG200.

The performance of the improved method was evaluated by three independent analysts using CRMs, and the practicability of validation using spiked samples was also demonstrated. The results of these analyses were in agreement with the target values specified in the guide- lines for the validation of test methods for metals. Thus, the present improved analytical method is valid for determining compliance with the provisional regulation value for methylmercury in fish.

\section{Acknowledgments}

This study was supported by a Health and Labour Sciences Research Grant for "Research Concerning Evaluation of the Intake of Toxic Substances such as Dioxins through Food and Associated Method Development" from the Ministry of Health, Labour, and Welfare of Japan.

\section{References}

1) Harada, M. Minamata disease: methylmercury poisoning in Japan caused by environmental pollution. Crit. Rev. Toxicol., 25, 1-24 (1995)

2) Clarkson, T. W., Magos, L., Myers, G. J. The toxicology of mercury-Current exposures and clinical manifestations. N. Engl. J. Med., 349, 1731-1737 (2003).

3) Itano, K. Mercury in seafood and assessment of risk. Seikatsu Eisei (J. Urban Living \& Health Assoc.), 51, 57-65 (2007).

4) Rai, R., Maher, W., Kirkowa, F. Measurement of inorganic and methylmercury in fish tissues by enzymatic hydrolysis and HPLC-ICP-MS. J. Anal. At. Spectrom., 11, 1560-1563 (2002)

5) Sakamoto, T., Akaki, K., Watanabe, T., Matsuda, R., Hiwaki, H. Development of the GC-MS method following phenylation to quantify methylmercury in foods. Bunseki Kagaku, 61, 327-333 (2012).

6) Hight, S. C. Rapid determination of methyl mercury in fish and shellfish: collaborative study. J. Assoc. Off. Anal. Chem., 70, 667-672 (1987) 